

\title{
A CIDADE IDEAL E UMA ALTERNATIVA DE OCUPAÇÃO PARA AS FAVELAS ${ }^{1}$
}

THE IDEAL CITY AND AN ALTERNATIVE FOR THE OCCUPATION OF FAVELAS

Isabel Campos Caldeira Brant ${ }^{2}$

\begin{abstract}
Resumo
Este artigo estabelece relações entre "cidade ideal" e cidade real através do fenômeno urbano das favelas. São consideradas as características de informalidade desses assentamentos, suas condições de irregularidade, as necessidades reais de seus habitantes e os padrões usuais de intervenção adotados no planejamento e desenvolvimento das cidades. Enfoca diferentes aspectos da cidade formal e informal, propondo uma alternativa de ocupação espacial como forma de solucionar seus conflitos, utilizando a tecnologia do presente associada às peculiaridades da própria comunidade.
\end{abstract}

Palavras-chave: Cidade ideal; Favela; Alternativa de ocupação; Desenvolvimento urbano; Qualidade de vida.

\begin{abstract}
This article establishes relations between "ideal city" and real city through the urban phenomenon of favelas (Brazilian slums). It considers their characteristics of informality and irregular conditions, as well as their inhabitants' true needs and the usual intervention methods adopted in city planning and development. Different aspects of formal and informal cities are focused on, so as to offer an alternative mode of spatial settlement as a solution to their conflicts, using current technology associated with each community's peculiarities.
\end{abstract}

Key words: Ideal city; Favelas (Slums); Alternative settlement; Urban development; Life quality. 
As favelas de encosta brasileiras constituem um fenômeno urbano que vem crescendo fortemente com o passar dos anos. No Brasil, as numerosas favelas - habitadas por aproximadamente 51,7 (DAVIS, 2006, p. 34) milhões de pessoas - são temas constantes em cursos de arquitetura e urbanismo. Isso não foi diferente durante a International Summer School. Nas palestras, os avanços das ações em desenvolvimento urbano na cidade formal em todo o mundo ficaram evidentes. Já na cidade informal, como é designada a favela, as abordagens predominantes que promovem esse desenvolvimento tem variado pouco nos últimos anos, principalmente no âmbito das ações públicas.

Nessas ações se inclui uma parte significativa da cooperação internacional voltada para o país, visando o desenvolvimento urbano. A ajuda financeira do Banco Mundial acontece desde a década de 1970, moldando uma realidade que "deu ao Banco enorme influência nas políticas urbanas nacionais, além de uma relação de patrocínio direto com as ONGs e comunidades faveladas locais; também permitiu ao Banco impor as suas próprias teorias como ortodoxia mundial da política urbana" (DAVIS, 2006, p. 79). Esse cenário tem se modificado, mas as entidades financeiras internacionais ainda exercem grande poder sobre ações de desenvolvimento urbano. Por esses e outros motivos, o desvirtuamento das reais questões por trás da favela e dos desejos de seus habitantes tornou-se um problema que se reflete diretamente sobre as práticas urbanísticas nesse ambiente. Por isso, ao longo da semana, questionaram-se muito os conceitos que são atribuídos quase automaticamente (ou culturalmente) à favela, aos seus habitantes, às suas necessidades, ao seu patrimônio, aos seus valores etc. e, principalmente, as decisões tomadas sem consultar seus habitantes.

Apesar dos crescentes esforços em se estudar a favela e produzir publicações sobre o tema, trata-se ainda de um tema difícil de analisar sob a ótica da produção teórica disponível sobre a cidade, a arquitetura, a arte e a história, porque se encontra à margem das sofisticadas discussões acerca da cidade formal.

"Antes de considerar a cidade em relação a categorias estéticas, é preciso considerá-la em relação às técnicas que a tornam não apenas concebível, mas projetada, e, portanto, logicamente, em relação aos procedimentos e às técnicas do projeto" (ARGAN, 1995, p. 75). Ao caracterizar a cidade como Gestaltung ao invés de Gestalt, Argan acaba excluindo a não-projetada favela da sua definição de cidade. Essa exclusão não é intencional, mas acontece muito. Isso porque as favelas ou "cidades informais" seguem outra lógica, muito diferente daquela da cidade que estamos habituados a estudar, perceber e experimentar diariamente. Isso dificulta a relação da favela com boa parte da produção acadêmica disponível, pois, não sem razão, exploram-se universos diferentes. Há ainda motivos perversos para essa exclusão: "Também podemos dizer que as ideias estão no lugar por isso mesmo: porque elas se aplicam a uma parcela da sociedade, reafirmando e reproduzindo desigualdades e privilégios" (MARICATO, 2000, p. 122).

A ocupação de favelas inicia-se pela invasão de propriedades públicas ou privadas, caracterizando-se como um espaço informal. 
Insere-se em um contexto de "segregação territorial e todos os corolários que a acompanham - falta de saneamento ambiental, riscos de desmoronamentos, risco de enchentes, violência - estão a ele vinculados" (MARICATO, 2000, p. 123). Isso, somado à condição social de seus habitantes, faz da favela um espaço marginalizado, desvalorizado e estereotipado pelos habitantes da cidade formal.

As favelas eram suprimidas dos mapas urbanos até meados da década de 1980. Durante muito tempo, achava-se que a remoção das favelas as faria desaparecerem. Na história do Brasil, esse tipo de atitude foi registrada desde muito cedo, sendo uma das mais conhecidas a ocorrida no Rio de Janeiro no Brasil pós1964: "O início do período militar caracterizou-se por uma atitude autoritária, com a remoção compulsória de assentamentos de invasores com a ajuda de forças de segurança pública (...) os militares arrasaram oitenta favelas e expulsaram quase 140 mil pobres dos morros que dominam o Rio" (DAVIS, 2006, p. 115 apud TASCHNER, Squatter settlements and slums in Brazil, p. 205). Depois, acreditava-se que construir moradias para os habitantes das favelas em outros locais da cidade seria a solução, ação ainda empregada em urbanizações em caso de falta de espaço na Vila para realocar habitantes de área de risco. Em seguida, foi percebido que as pessoas queriam permanecer ali pelos mais diversos motivos - laços sociais, econômicos etc. - e acabavam voltando. Atualmente, percebe-se que a construção de conjuntos habitacionais iguais, imutáveis e sem a participação da comunidade, também não apresenta bons resultados qualitativos.

O desenvolvimento urbano democrático e a busca por uma cidade ideal apresentam uma série de dificuldades em se tratando da favela. "A chamada cidade ideal nada mais é que um ponto de referência em relação ao qual se medem os problemas da cidade real" (ARGAN, 1995, p. 73). Os problemas atuais da cidade real são inúmeros. Inserida no novo contexto de crise ambiental e energética, e no quadro que se delineia de crescimento do tecido urbano e superpopulações, as novas demandas do espaço e do homem, associadas à falta de recursos, entram na questão de uma forma inédita. Considerando que a maior parte das pessoas não inclui as favelas em suas "cidades ideais" (independentemente da sua transformação em espaços prósperos e dignos), lida-se aqui, principalmente, com a "cidade real."

"Em geral, o desenho da cidade ideal implica o pensamento de que, na cidade, realiza-se um valor de qualidade que permanece praticamente imutável com a mudança da quantidade, na medida em que, por postulado, qualidade e quantidade sejam entidades proporcionais" (ARGAN, 1995, p. 74). Tendo em vista o horizonte superpopulacional, aliado ao crescimento desenfreado que vem ocorrendo nas favelas, o desafio é não apenas aumentar a qualidade da favela, mas também aumentar significativamente a quantidade de pessoas a serem beneficiadas pelas mudanças. Trata-se de um problema que não possui índices aceitáveis de qualidade e quantidade com uma proporção a ser mantida.

A quantidade em projetos em favelas se refere, em geral, ao número de habitantes do local, número estimado de crescimento desse tipo de ocupação, número de habitantes por metro quadrado etc. Já a qualidade: insegurança, insalubridade, margina- 
lidade, ilegalidade, ilegitimidade, inacessibilidade, entre outros. Existem ainda qualidades a serem mantidas e fortalecidas, como os laços sociais, a identificação do morador com o lugar, o patrimônio imaterial, a localização etc. Entre essas questões um bom exemplo seria: como manter as pessoas onde elas estão e ainda assim permitir o crescimento populacional?

"A causa da situação crítica da cidade, hoje, é em grande parte determinada pelo fato de que seu informalismo não tem relação alguma com o formalismo programático das cidades ideais" (ARGAN, 1995, p. 76). Esse "informalismo" se refere às inúmeras formas que uma cidade pode adquirir na experiência de quem nela vive, e não ao sentido que utilizamos no Brasil, da ilegalidade. Seguindo o conceito de Argan, pode-se voltar a atenção para as experiências de quem vive nas cidades brasileiras. A maioria da população da cidade vivencia apenas a cidade formal. No caso das favelas, os sujeitos são aqueles que experimentam tanto a cidade formal quanto a favela. Assim, a relação dos habitantes da favela com o espaço é totalmente diversa da do cidadão habitante da cidade formal. Apresentam uma visão de espaço, ordem, conforto e satisfação diferenciada, tornando sua participação nas decisões projetuais muito importante para a adequação do projeto a essa perspectiva.

A desordem espacial característica da favela e a má qualidade das habitações repercutem nas condições de vida de seus habitantes, agravando questões como a locomoção, a acessibilidade, a insegurança, a pouca diversidade de usos, a insalubridade e a própria baixa estima da população.

Através da análise do projeto intitulado "A micro community solving global problems"1 (posteriormente desenvolvido para a $7^{\mathrm{a}}$ Bienal Internacional de Arquitetura de São Paulo), apresenta-se uma alternativa ao modo de intervenção de arquitetos e urbanistas em favelas de encosta, típicas da região Sudeste do país e frequentemente lindeiras a áreas nobres das cidades.

"Naturalmente, toda intervenção urbanística e de construção na cidade implica, junto da necessidade de responder a uma exigência atual, uma atitude, uma obrigação de intervenção e, portanto, uma avaliação da condição objetiva e presente da cidade" (ARGAN, 1995, p. 77). O estudo de implantação do projeto foi realizado na conurbação de favelas "Aglomerado da Serra", o maior aglomerado de vilas de Belo Horizonte, com população estimada em 50.000 habitantes. Esse local foi escolhido para se obter uma visualização do sistema de ocupação proposto e para a verificação da aplicação da construção em um terreno real. Cerca de $20 \%$ da população de Belo Horizonte vive em favelas. Essa proporção está crescendo e as intervenções urbanísticas passam longe de obter resultados ideais. Há uma urgência de projetos urbanos nas favelas.

Se a "ordem urbanística reflete a ordem social" (ARGAN, 1995, p. 74) e se os "ritmos existenciais das cidades são muitas vezes distintos segundo as classes sociais" (ARGAN, 1995, p. 75), os arquitetos urbanistas têm a missão de ordenar ou desordenar esse ritmo para que as "distinções" sejam mais diferenciações coerentes do que exclusões injustas, visando ao menos uma "cidade real" que de fato exista para todos. Como as intervenções

\author{
1. Projeto enviado ao Concurso \\ Internacional de Estudantes Futures \\ of Cities, organizado pela IFHP \\ (International Federation for Housing \\ and Planning), no qual recebeu menção \\ honrosa. Autoria dos estudantes \\ Bernardo Araújo, Éder Andrés, Isabel \\ Brant, Mateus Andreatta e Thiago \\ Campos, da Escola de Arquitetura da \\ UFMG, orientados pela Profa $\operatorname{Dr}^{a}$ Maria \\ Lúcia Malard, em 2007.
}

Cadernos de Arquitetura e Urbanismo, v.16, n.18+19, 2009 

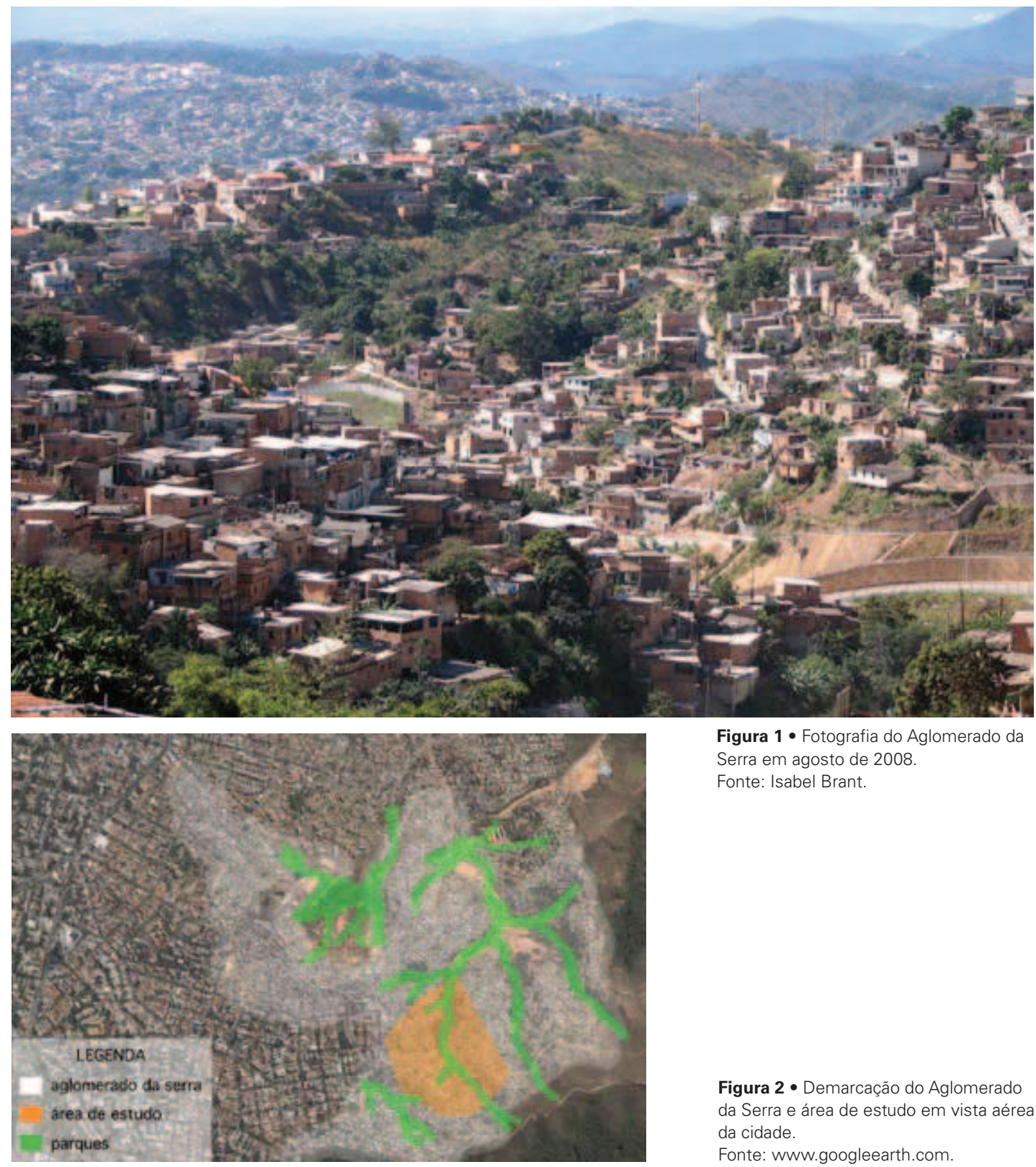

Figura 1 • Fotografia do Aglomerado da Serra em agosto de 2008.

Fonte: Isabel Brant.

Figura 2 • Demarcação do Aglomerado da Serra e área de estudo em vista aérea da cidade.

Fonte: www.googleearth.com.

necessárias para a melhora efetiva das condições de vida dos habitantes da favela é uma questão complexa que engloba muitas áreas de conhecimento, o projeto apresentado pretende preencher algumas das lacunas que cabem ao profissional arquiteto urbanista, tendo como objetivo principal a oferta de espaços de qualidade para se viver, conviver, crescer e prosperar, facilitando a inclusão social e a democratização do espaço.

Se por um lado a cidade, "no decorrer de sua existência, sofreu modificações, alterações, acréscimos, diminuições, deformações, às vezes verdadeiras crises destrutivas" (ARGAN, 1995, p. 74), por outro cabe aos arquitetos urbanistas conhecer esses processos, entender suas causas e colocar em prática seus ensinamentos sempre que possível, de modo que a história da ci-

Cadernos de Arquitetura e Urbanismo, v.16, n.18+19, 2009 
dade sirva de parâmetro prático a ser seguido (ou não) para o futuro. O desafio está nesse reconhecimento e na aplicação projetual das teorias urbanas que nos parecem coerentes. No caso do projeto aqui apresentado, a "Ville Spatiale" de Yona Friedman foi a teoria urbana que inspirou a solução, cujo grande diferencial são os "lotes aéreos".

Os "historiadores da cidade devem exercer uma função essencial, de decisão, sua ação não é apenas de proteção ou censura, mas deve entrar nas escolhas de plano e projeto urbanístico" (ARGAN, 1995, p. 77). As tendências recentes tomam como valores histórico-ideológicos mais relevantes não "apenas o monumento, mas também a casa de moradia ou a oficina artesanal e, em geral, mais o tecido do que o núcleo representativo" (ARGAN, 1995, p. 77). Da mesma forma, os arquitetos devem ser capazes de perceber o que vale preservar e "uma vez que nem tudo pode ser conservado, é preciso estabelecer o que deve ser preservado, custe o que custar" (ARGAN, 1995, p. 77). No contexto do Aglomerado, a preservação deve ser a do direito das pessoas de permanecerem ali com dignidade e com os benefícios que a vida urbana tem a oferecer. Foi buscada a preservação das relações benéficas dentro daquele espaço, dos aspectos positivos consolidados e das práticas sociais positivas através de um projeto cuja renovação material/urbana e arquitetônica é muito grande. Tendo isso em vista, algumas decisões principais foram tomadas.

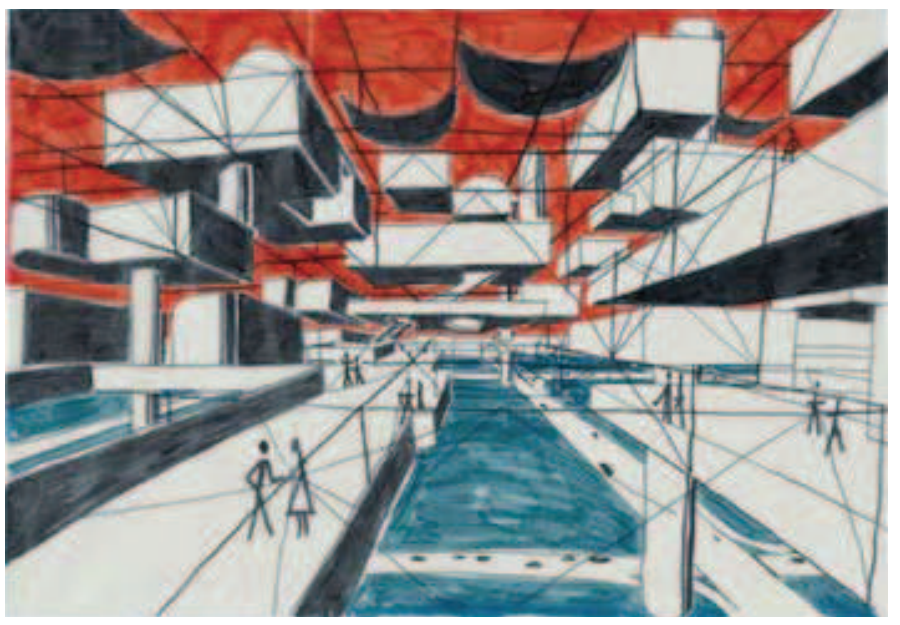

Uma delas foi a de criar espaços públicos com mais variações de tamanho e localização, mais diversos, com mais possibilidades, espalhados por toda a favela, acrescentados aos grandes espaços abertos que oferecem quadras de futebol. Muitas favelas apresentam deficiência de espaços públicos. Ao terem acesso a espaços públicos como praças, parques, hortas comunitárias, mirantes etc., os habitantes têm a oportunidade de usufruírem de todos os benefícios pedagógicos e recreativos inerentes a esses espaços. Exercitam a convivência, a troca, a tolerância, a cordialidade, o diálogo e o aprendizado, num contexto generalizado de fortalecimento das relações humanas. Além disso, os espaços públicos dão oportunidade para manifestações da rica produção cultural da comunidade e alternativas para a socializa-
Figura 3 • Croqui da "Ville Spatiale", Yona Friedman.

Fonte: www.moma.org/collection.

Cadernos de Arquitetura e Urbanismo, v.16, n.18+19, 2009 
ção dos jovens. O objetivo é que o maior patrimônio da favela - imaterial e humano - seja atendido espacialmente através da criação de espaços mais favoráveis à interação, com uma maior variação dos espaços ofertados, tanto em dimensões como em ambiência, acesso, visadas e localização.

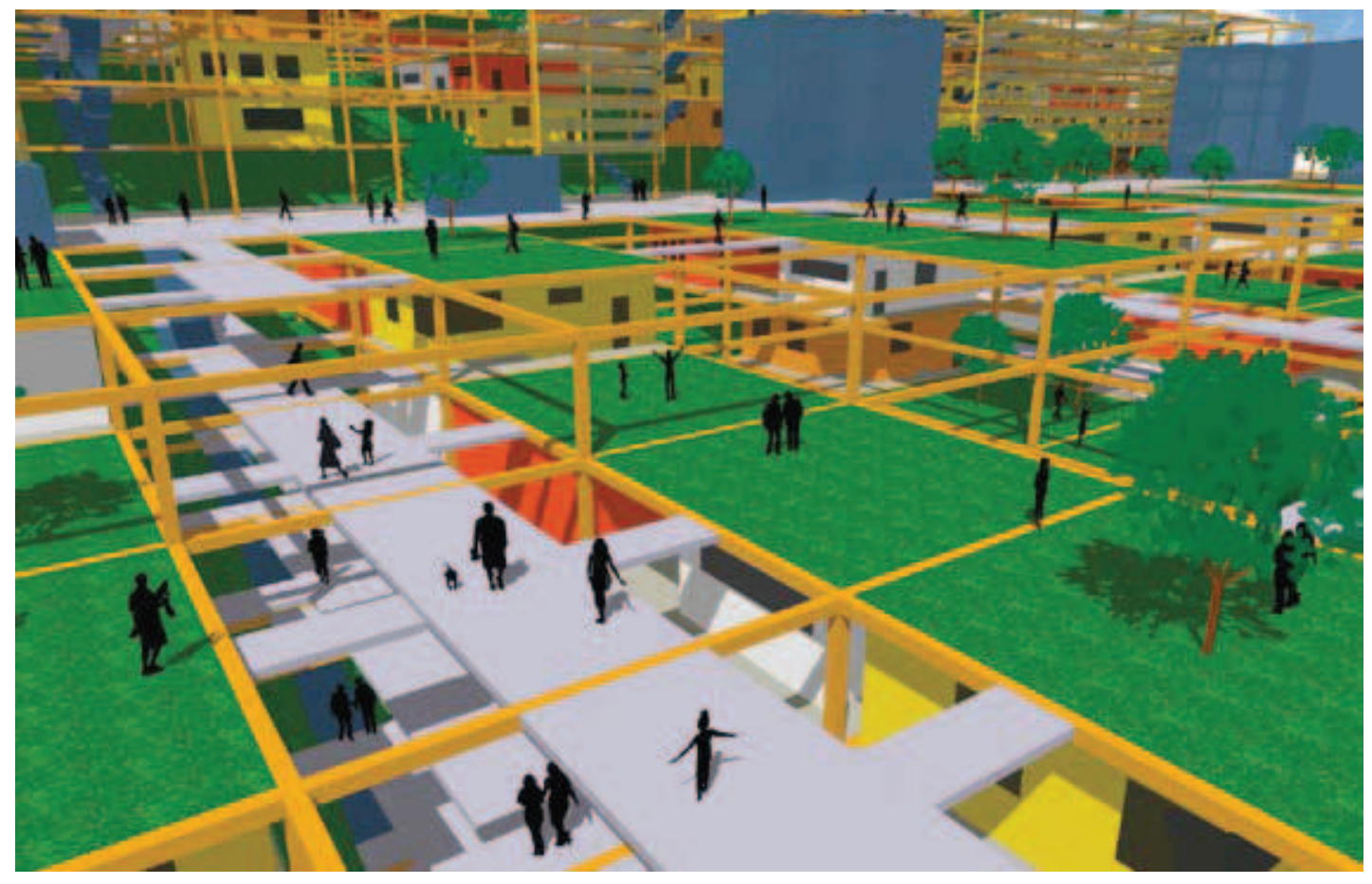

Outra decisão importante foi a de legitimação. O Aglomerado da Serra ocupa uma área onde $80 \%$ é propriedade estadual e $20 \%$ particular. A proposta assume que os moradores têm relações sociais importantes com o centro da cidade e com as áreas contíguas à favela. Experiências anteriores mostram que a relocação de habitantes de favelas para conjuntos habitacionais afastados de seus locais de origem torna os locais de trabalho inacessíveis e quebra os laços sociais consolidados na favela. Assim, pressupõe-se que o primeiro passo para resolver o problema das favelas é legitimar a sua ocupação pela população de baixa renda, proporcionando condições de permanência aos seus habitantes. Isso implica a formalização das favelas, levando toda a rede de serviços, aproveitando seu potencial de geração de riquezas e alterando sua condição de dormitório de mão-deobra. Trata-se da aceitação desse fenômeno urbano como um fator indispensável para seu desenvolvimento e a superação dos problemas presentes nesse tipo de ocupação.

Por último, na escala arquitetônica, observa-se que a tipologia de "casa" utilizada na favela, ao ser substituída pela tipologia de prédios iguais para todos, cria muita resistência. Para evitar esse problema, foi pensada uma tipologia que permitisse a construção de casas da forma como os moradores desejassem (dando flexibilidade para a construção dos habituais e necessários "puxados") com a garantia de uma estrutura vertical segura que ainda permitisse a liberação de espaço para crescimento popu-
Figura 4 - Perspectiva da proposta. Fonte: Isabel Brant. 
lacional, passagem de vias, circulação de pedestres e criação de espaços públicos. O controle de qualidade da arquitetura deve nascer de um equilíbrio entre a autonomia construtiva já instituída na cultura dos habitantes da favela e a disponibilidade de profissionais para auxílio técnico à comunidade.

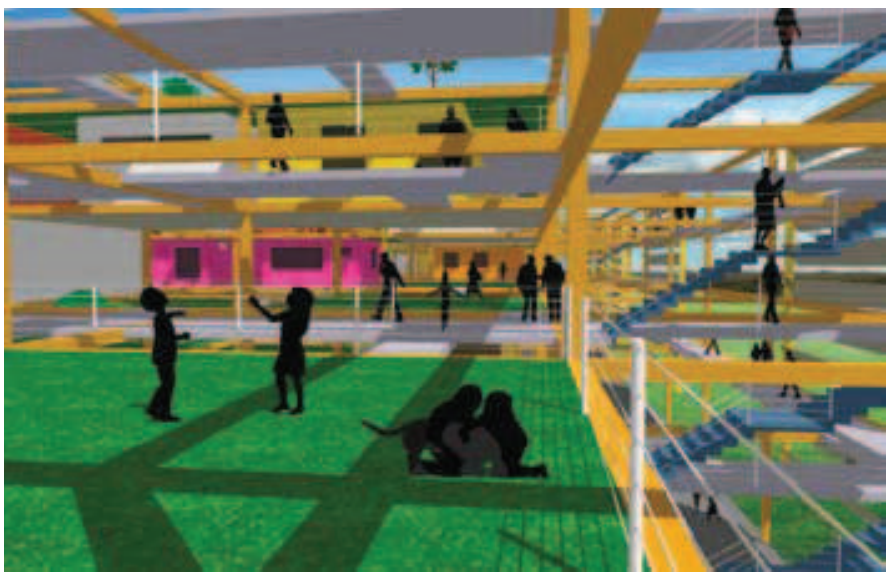

Através de uma grelha estrutural, o projeto pretende solucionar as cinco questões principais: habitação, acessibilidade, segurança, uso e salubridade, transformando os entraves espaciais e melhorando as condições de afirmação dessa comunidade na cidade.

A proposta de habitação é a de oferta de lotes aéreos que vão se tornando públicos ou privados à medida que se dá a ocupação. Em contraposição à concentração dos espaços públicos em alguma região da área de intervenção, optou-se por uma distribuição constante, através de espaços menores constituintes da estrutura de cada habitação, mantendo seu caráter público em certas partes e gerando espaços semipúblicos, dependendo da forma de ocupação dessa estrutura. Essa pulverização dos espaços públicos apresentou-se como a melhor solução tanto pelo modo de ocupação característico da favela, quanto pela participação necessária da população para manter a configuração proposta.
Figura $\mathbf{5} \bullet$ Perspectiva da proposta. Fonte: Isabel Brant.
Figura 6 • Implantação das edificações na área de estudo (atual e proposta). Fonte: Isabel Brant.

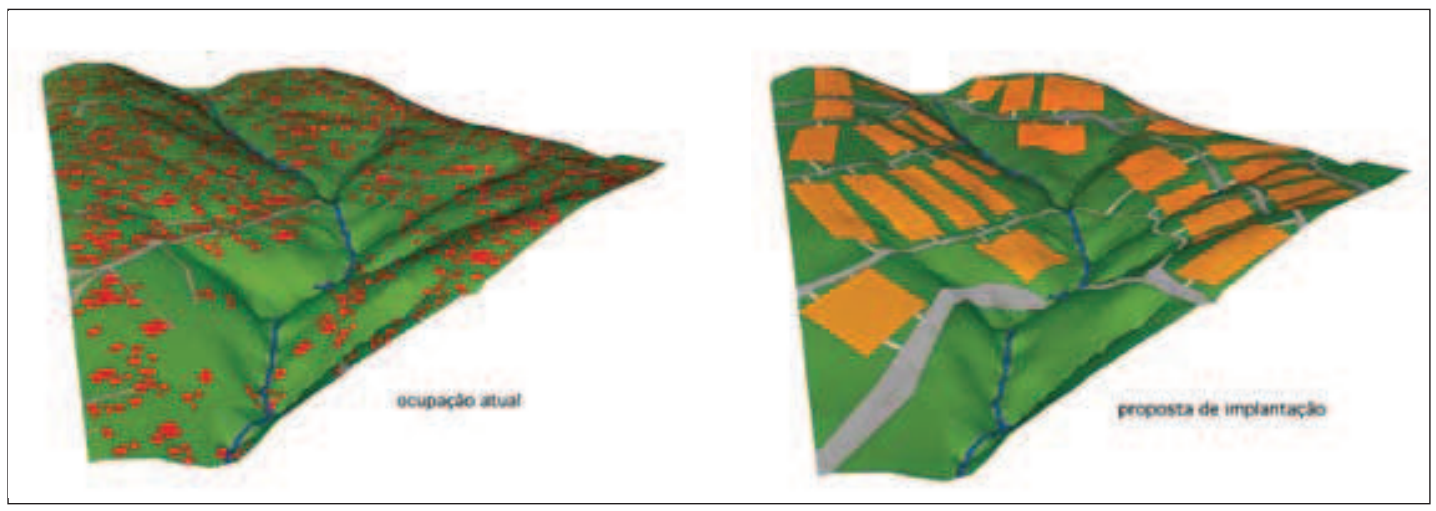

Uma porcentagem máxima de ocupação por áreas privadas é fixada em $70 \%$, sendo o restante área pública - para utilização como hortas, quadras, pátios, jardins, locais de encontro etc. A fiscalização desse limite seria feita pela própria população, garantindo seus espaços de lazer e encontro. Essa regra ocorre em re- 
lação ao número de lotes presentes em cada grelha, e não à sua localização. Cada novo morador escolhe em qual lote irá morar, além de ter liberdade de construir sua moradia da forma que quiser, respeitando alguns limites bastante flexíveis. Assim, cada grelha pode ser ocupada de forma diferente. Essas características evitam a padronização das habitações e a homogeneização da paisagem que costuma acontecer nas habitações propostas normalmente para favelas.

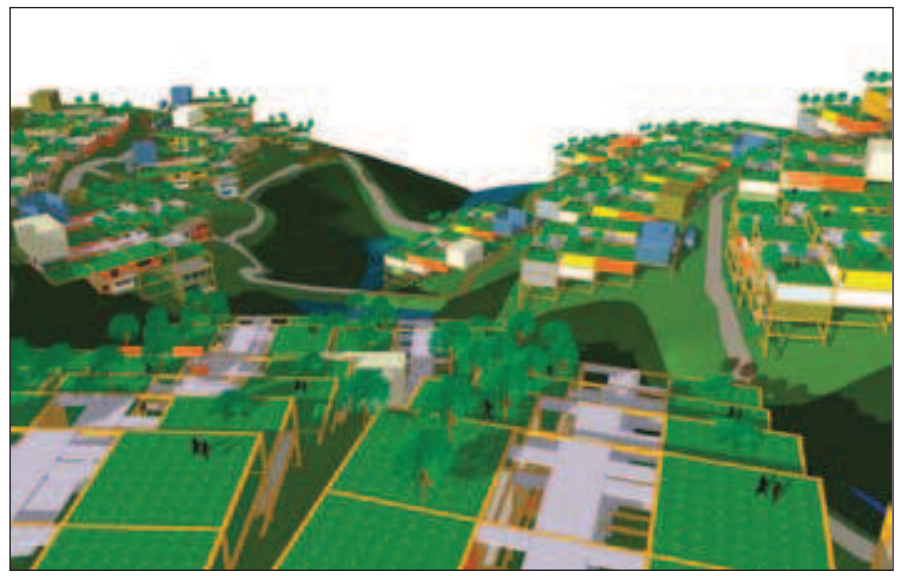

A ocupação da grelha é flexível e as variações de ocupação geram diferentes conformações espaciais: a concentração das moradias libera lotes contíguos que repercutem em amplos espaços públicos, assim como uma distribuição mais esparsa das moradias gera vários espaços semipúblicos. O pavimento superior de todas as grelhas é liberado para espaços públicos e edificações institucionais como escolas, postos de saúde e centros de atividades educativas.

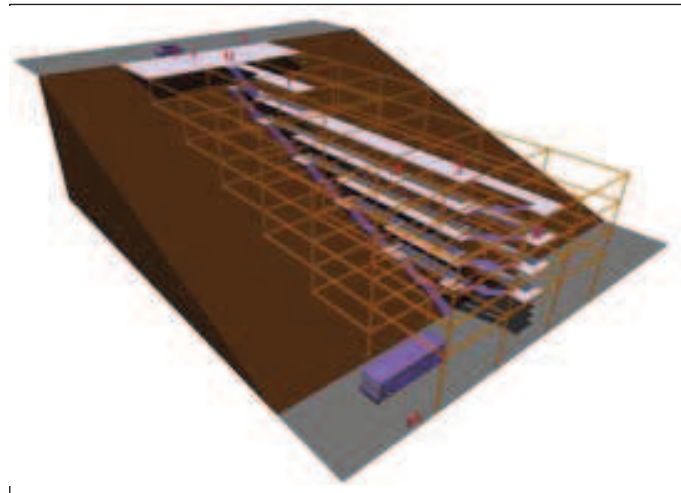

A modulação estrutural garante ventilação e iluminação adequadas, assim como estruturas econômicas e seguras, eliminando as constantes ameaças de deslizamento na época de chuvas: "Os solos lateríticos muito desgastados sob as favelas das encostas de Belo Horizonte e de outras cidades brasileiras são catastroficamente suscetíveis a deslizamentos e desabamentos de terra" (DAVIS, 2006, p. 128 apud GALVÃO; VIANA, 2003, p. 82-89). Sua forma segue a topografia, ocupando o terreno de forma mais eficiente. A verticalização dos lotes possibilita a ma-
Figura 7 - Perspectiva da proposta. Fonte: Isabel Brant. 
nutenção da densidade populacional com ganhos em espaço público. O núcleo fixo de circulação substitui as ruelas estreitas e íngremes da favela, articulando as ruas principais e melhorando a acessibilidade e segurança. Essa circulação pública também dá acesso aos espaços privados das habitações através de travessias semiprivadas. Há elevadores em alguns núcleos para permitir a acessibilidade universal. Esses elevadores funcionam com a energia gerada por barragens localizadas no parque proposto em torno do Córrego Camargos.

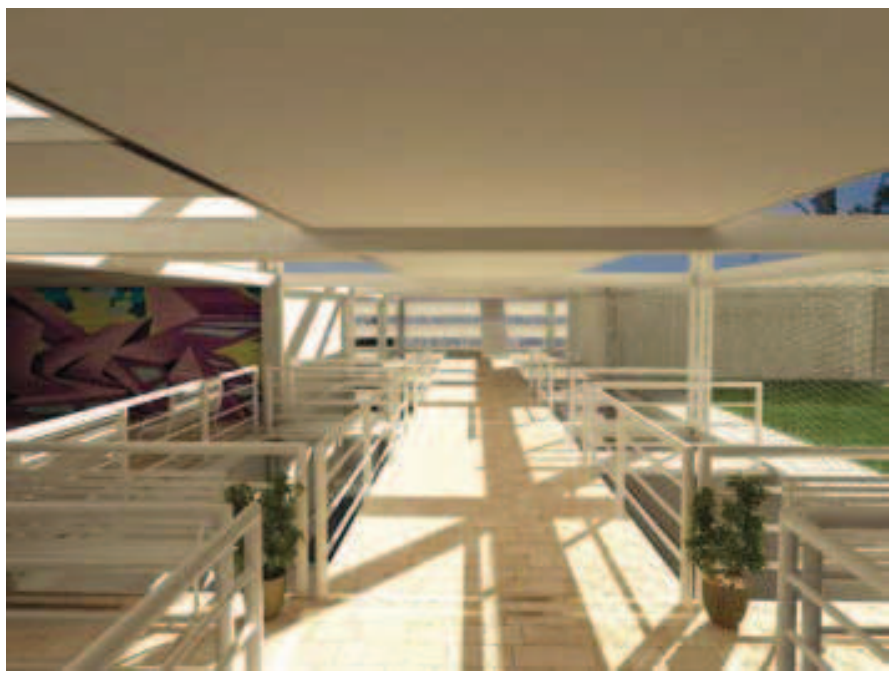

Além dos espaços públicos formados dentro das grelhas, o projeto ainda prevê a criação de parques públicos e áreas de preservação ambiental ao longo dos talvegues e fundos de vale. A definição desses locais garante a preservação das nascentes e dos cursos d'água existentes, além de impedir a ocupação de áreas de risco, já que tais regiões normalmente apresentam declividades acima de $50 \%$ e costumam apresentar risco de deslizamentos. Ao longo do córrego haveria barragens geradoras de energia que controlariam a vazão do curso d'água, além de terem um grande potencial como área de recreação e de permitirem a passagem de uma encosta para a outra do vale, conectando as Vilas. Os parques localizados no limite entre o Aglomerado e a cidade formal seriam áreas de transição, promovendo uma nova relação entre eles.

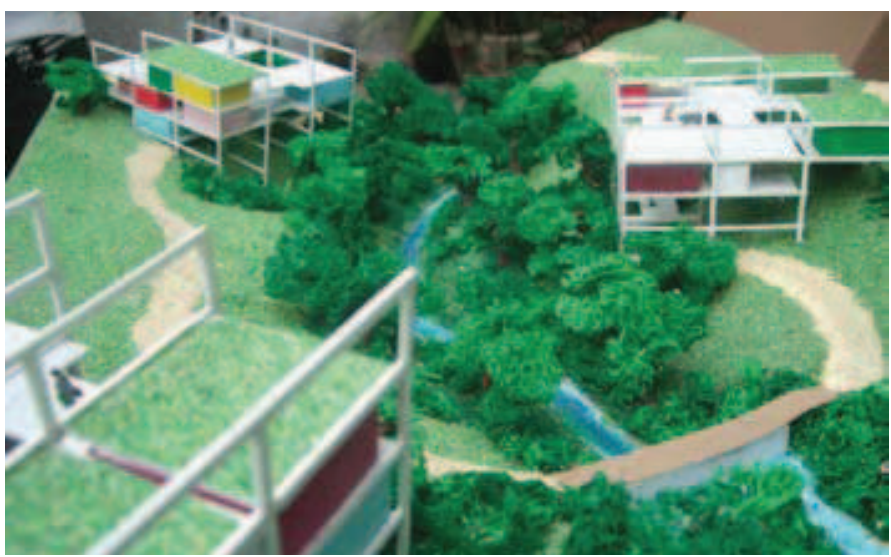

Figura 9 - Perspectiva da proposta. Fonte: Isabel Brant.

Figura 10 - Fotografia da maquete física da proposta.

Fonte: Isabel Brant. 


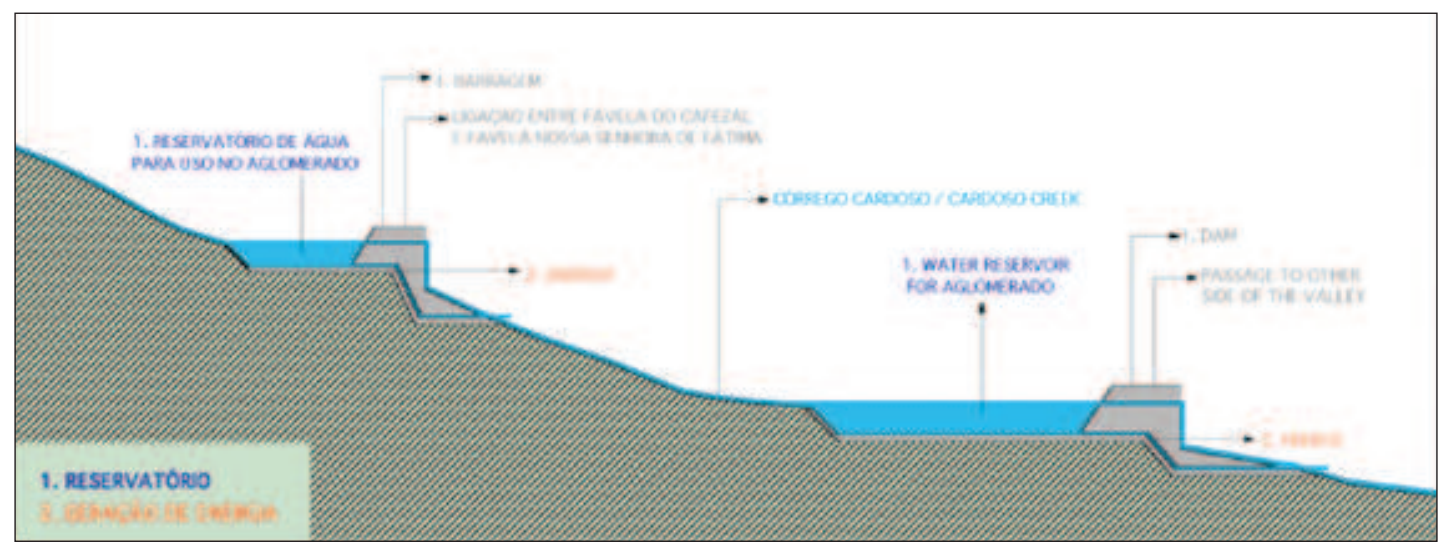

Figura 11 - Esquema de funcionamento das barragens.

Fonte: Isabel Brant.

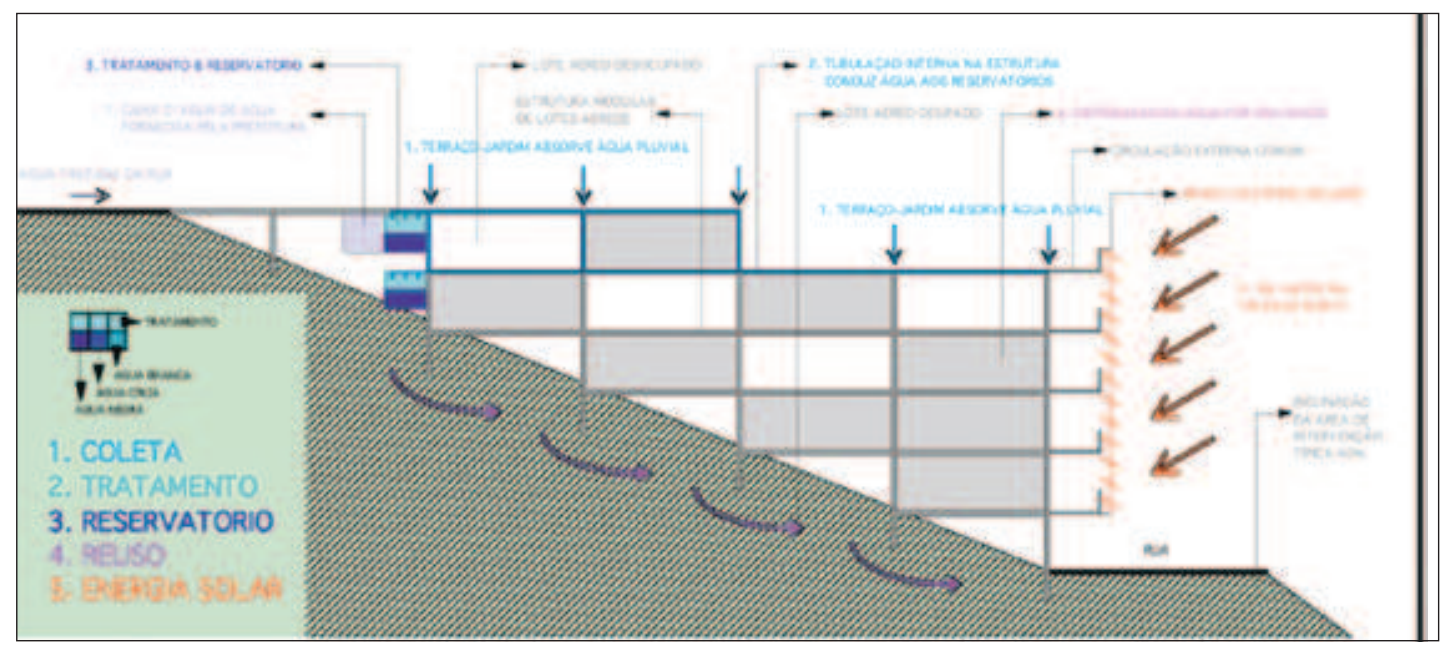

O sistema de habitação é ambientalmente sustentável, aproveitando as condições naturais de Belo Horizonte, como a abundante luz solar e os níveis altos de precipitação. O sistema tem $100 \%$ de reúso de água, terraços jardins coletores de água pluvial, brises com coletores solares e uso da gravidade para redistribuição da água na favela.

A substituição das habitações da favela pelo modelo aqui proposto seria feita de forma gradual, pelo regime de autogestão comunitária. Além disso, nem toda a favela seria substituída, o que ficaria a critério dos habitantes e planejadores, através de um consenso. As associações comunitárias sediadas no Aglomerado da Serra estabeleceriam uma parceria com a Prefeitura e se candidatariam a créditos oferecidos por instituições públicas a populações de baixa renda para a construção de habitações. A Prefeitura promoveria o remembramento e regularização fundiária dos terrenos e daria suporte financeiro para que as associações contratassem assistências técnicas, tal qual vem sendo feito em outros empreendimentos para a população de baixa renda financiados pela Caixa em Belo Horizonte. As assistências técnicas elaborariam os projetos e as obras, com a participação da comunidade. Enquanto aguardassem a construção das novas moradias, as famílias rece-
Figura 12 • Esquema de funcionamento da habitação.

Fonte: Isabel Brant. 
beriam da Prefeitura uma bolsa aluguel, nos moldes praticados para os casos de desabrigados das chuvas.

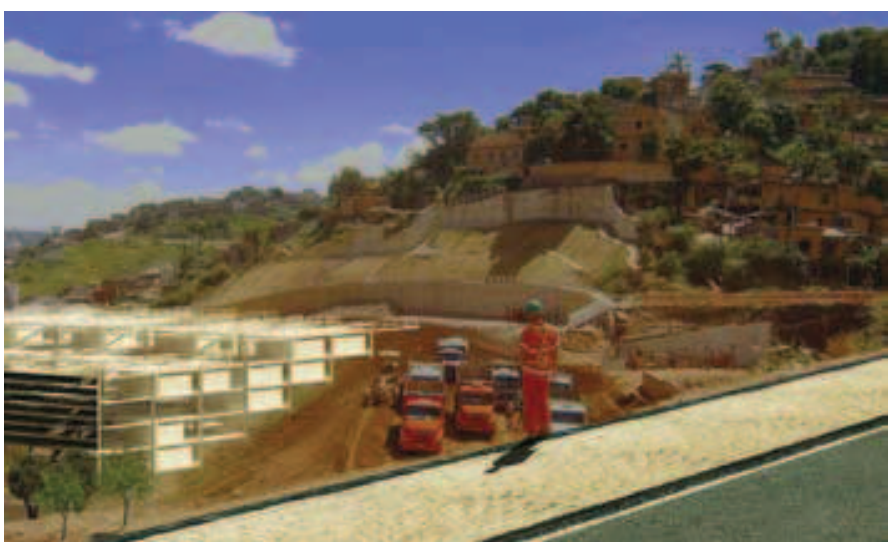

Assim como na formação das cidades industriais, a migração para os grandes centros urbanos causou uma grande mudança em termos de quantidade versus qualidade. No Brasil, ainda que a migração tenha diminuído drasticamente, a transformação mais significativa do nascimento do fenômeno urbano da favelização já está instituída na nossa realidade. Quando Argan diz, sobre centros históricos, "exatamente pelo fato de estarem como que enquistados no interior das cidades modernas e submetidos a um regime jurídico especial, os centros históricos passam por uma gravíssima condição de perigo" (ARGAN, 1995, p. 79), é impossível não comparar com a favela. No entanto, os centros históricos são espaços de prestígio dentro da cidade e estão sendo degradados por motivos muito diferentes dos da favela, que já nasceu degradada, marginal. Uma preocupação de Argan a respeito da recuperação de áreas degradadas tangencia um problema que pode vir a ocorrer em favelas transformadas: a gentrificação. "As próprias classes originais constituem um bem que deve ser protegido" (ARGAN, 1995, p. 79).

De fato, "a cidade real reflete as dificuldades do fazer a arte e as circunstâncias contraditórias do mundo em que se faz" (ARGAN, 1995, p. 74). Uma dessas circunstâncias contraditórias é a evolução da tecnologia, da economia, dos direitos humanos e da comunicação enquanto um bilhão de pessoas vivem em ocupações similares às favelas brasileiras. Para que o desenvolvimento urbano permeie espaços marginalizados da cidade, tornam-se necessárias abordagens mais direcionadas e inventivas. Um fenômeno urbano como a favela não pode ser encarado da mesma maneira que a cidade formal. As soluções de seus problemas requerem novas abordagens e certo desapego em relação às práticas usuais.

Ao transformar o espaço das favelas aspira-se a um "desenvolvimento coerente com sua realidade histórica, de modo que, mesmo na diversidade das organizações e dos níveis, uma articulação funcional assegure o dinamismo de todo o tecido urbano" (ARGAN, 1995, p. 81). É preciso também refletir sobre o dinamismo existente entre favela e cidade formal, no qual a favela serve de dormitório de mão-de-obra barata para o entorno que a exclui. Dinamismo não é necessariamente positivo. "Não há dúvida de que,
Figura 13 • Fotoinserção da proposta. Fonte: Isabel Brant. 


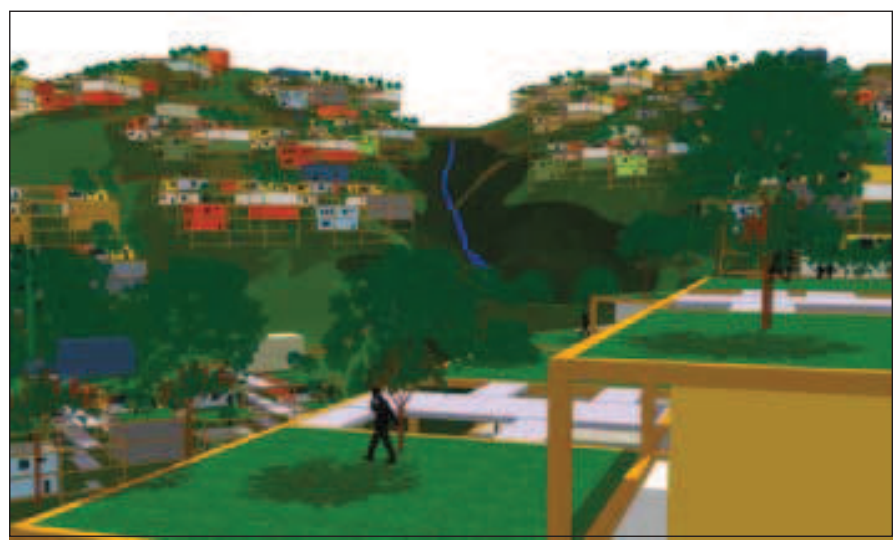

quando um tecido está praticamente necrosado, a recuperação social e funcional é bastante difícil, ainda mais se não solicitada pelo desejo dos nativos" (ARGAN, 1995, p. 80). Sabe-se que a transformação espacial não alcança resultados integralmente satisfatórios se não caminhar junto com transformações sociais, econômicas e políticas. A elaboração de propostas alternativas e experimentações devem "passar doravante da fase de pioneirismo à da utilização generalizada" (ARGAN, 1995, p. 80).

Condições dignas de habitação e vida urbana melhoram a qualidade de vida das pessoas, enriquecendo as relações humanas e facilitando a construção de um futuro melhor. Ao se eliminar o caráter marginalizado das favelas, dando condições de permanência aos seus habitantes, acredita-se na possibilidade de inclusão e recomeço.

\section{Referências}

ARGAN, Giulio Carlo. História da arte como história da cidade. 3. ed. São Paulo: Martins Fontes, 1995.

RANTES, Otília Beatriz Fiori; VAINER, Carlos; MARICATO, Ermínia. A cidade do pensamento único: desmanchando consensos. 3. ed. Petrópolis: Vozes, 2000. (Zero à esquerda).

CALVINO, Ítalo. As cidades invisíveis. 8. ed. São Paulo: Companhia das Letras, 1990.

DAVIS, Mike. Planeta favela. São Paulo: Boitempo, 2006.

FRIEDMAN, Yona. Pro Domo. Barcelona: Actar, 2006.

VIANA, C. S.; GALVÃO, T.C.B. An erosion hazards index for lateritic soils. Natural Hazards Review, USA, v. 4, n. 2, p. 82-89, 2003.

\section{Endereço para correspondência}

Isabel Campos Caldeira Brant Rua Sobral, 557 - Santa Lúcia 30360-410 - Belo Horizonte - MG isabelbrant@gmail.com
Figura 13 - Figura 14 - Perspectiva da proposta.

Fonte: Isabel Brant. 